\title{
El imaginario artístico de "lo vasco". Prácticas y políticas culturales a finales del siglo XX
}

\author{
The Artistic Imaginary of "Basquesness". Cultural Practices and \\ Policies at the End of the $20^{\text {th }}$ Century
}

\author{
ANE LEKUONA-MARISCAL \\ Universidad del País Vasco \\ ane.lecuona@ehu.eus
}

Resumen: El artículo analiza el cruce iniciado a partir de los años de la transición entre el discurso cultural del Gobierno Vasco y la difusión reiterada del lenguaje plástico de los escultores que habían participado en los años sesenta en el grupo guipuzcoano Gaur. Se estudian las razones que motivaron esta unión entre las directrices políticas y el imaginario artístico, así como los cambios que se han ido produciendo hasta la actualidad y sus efectos. Por otra parte, se analiza la relación entre dicho fenómeno y la configuración de la historia del arte del País Vasco de la segunda mitad del siglo Xx.

Palabras clave: País Vasco, Transición, PNV-EAJ, Historia del arte, Cultura institucional.

Abstract: This article analyses the crossover that began in the years of the Spanish Political Transition between the cultural discourse of the Basque Government and the repeated dissemination of the plastic language of the sculptors who had participated in the Gaur group in the 1960s. We examine the reasons that motivated this union between political guidelines and the artistic imagination, as well as the changes that have taken place up to the present time and their effects. Furthermore, it analyzes the relationship between this phenomenon and the configuration of the Basque art history of the second half of the $20^{\text {th }}$ century.

Keywords: Basque Country, Transition, PNV-EAJ, Art History, Institutional Culture.

Recibido: 27 de enero de 2020; aceptado: 1 de noviembre 2020; publicado: 31 de marzo de 2021.

Revista Historia Autónoma, 18 (2021), pp. 165-182

e-ISSN: 2254-8726; https://doi.org/10.15366/rha2021.18.009 


\section{Cultura y visualidad en el País Vasco de la transición}

El éxito logrado por el Partido Nacionalista Vasco (PNV) en las primeras elecciones democráticas de 1977 daba comienzo al proyecto del Estatuto de Autonomía de Guernica. Tras casi cuarenta años de dictadura y en el seno de una sociedad de gran agitación ${ }^{1}$ y violentada por la presencia del grupo terrorista ETA, el ordenamiento vino a simbolizar la superación definitiva del franquismo y la convivencia de la comunidad vasca en paz y libertad ${ }^{2}$. De esta manera, la reinstauración del organismo del Gobierno Vasco significó que los impulsos nacionalistas iniciados años atrás salieran al ámbito público y se plasmaran en todos los aspectos de la sociedad, también en la forma de concebir la cultura3 ${ }^{3}$. La cesión de trasferencias por parte del gobierno central posibilitó la creación y el restablecimiento de diferentes entidades públicas y privadas a favor de la difusión, la recuperación y la defensa de la cultura vasca, en especial, a la reanimación del euskera ${ }^{4}$. Entre otras iniciativas, se institucionalizó el sistema del bilingüismo oficial, se reinstauraron diferentes entidades promotoras ligadas a este ${ }^{5}$, se fundó la Orquesta Sinfónica de Euskadi ${ }^{6}$ o surgieron nuevos medios de comunicación como la Radio Televisión Vasca-EITB ${ }^{7}$ con programación en euskera. En el ámbito de las artes plásticas, se configuraron nuevas entidades como Enkoari ${ }^{8}$, Kulturgintza ${ }^{9}$, la Fundación Faustino Orbegozo ${ }^{10}$ o el concurso Gure Artea ${ }^{11}$.

No obstante, el apoyo hacia las propuestas culturales nacionalistas se vio reflejado también en otras esferas como, por ejemplo, en diversas representaciones populares. Diferentes símbolos relacionados con el imaginario vasco como la ikurriña ${ }^{12}$ y sus colores, la iconografía vinculada al mundo rural, la silueta de las siete provincias del País Vasco, la txalaparta, la hoja del roble, el lauburu o la boina fueron ocupando el espacio público (fig. 1.). Pero el ambiente

\footnotetext{
${ }^{1}$ Junto a la esfera de la contracultura, fue entonces cuando emergieron movimientos organizados como el feminista, el ecologista o el pacifista. Para mayor información sobre estas experiencias consultar: Beorlegui Zarranz, David, Transición y melancolía. La experiencia del desencanto en el País Vasco (1976-1986), Madrid, Postmetropolis Editorial, 2017.

${ }^{2}$ Mees, Ludger, “Guernica/Gernika como símbolo”, en Historia Contemporánea, 35 (2007), pp. 529-557.

${ }^{3}$ Martínez de Albeniz, Iñaki, "La política cultural en el País Vasco: del gobierno de la cultura a la gobernanza cultural", en RIPS: Revista de Investigaciones Políticas y Sociológicas, 11, 3 (2012), pp. 149-171.

${ }^{4}$ Vadillo Eguino, Miren, "Transformaciones artísticas e instauración de un modelo cultural en el nuevo Gobierno Vasco (1979-1984)", en Ondare, 26 (2008), pp. 217-233.

${ }^{5}$ Por ejemplo, Euskaltzaindia, La Real Academia de la Lengua Vasca, reconocida en 1976, Eusko Ikazkuntza, La Sociedad de Estudios Vascos, ambas reconocidas en 1976, o el Instituto HABE creado en 1981.

${ }^{6}$ Creada en 1982.

${ }^{7}$ Creada en 1982.

${ }^{8}$ Creada en 1976

${ }^{9}$ Creada en 1977.

${ }^{10}$ Creada en 1978.

${ }^{11}$ Traducido como "Nuestro Arte", el concurso creado en 1982 fue una de las contribuciones principales de Néstor Basterretxea en su cargo como asesor artístico del Gobierno Vasco. El evento sigue siendo en la actualidad el más importante y reconocido de la región.

${ }_{12}$ También el Gobierno Vasco restableció la ikurriña y el himno (Eusko Abendaren Ereserkia), dos símbolos concebidos por Sabino Arana. Arrieta Alberdi, Leyre, "Por los derechos del pueblo vasco. El PNV en la Transición (1975-1980)", en Historia del presente, 19 (2012), pp. 39-52.
} 
cultural motivó la creación y la actualización de nuevos símbolos que vinieran a reflejar esta misma idea identitaria. Ejemplo evidente de ello fue la reactivación que vivió la llamada "grafía vasca", la cual fue empleada tanto en iniciativas sociales como en la imagen corporativa de diferentes entidades oficiales y privadas que quisieron destacar su adhesión al territorio ${ }^{13}$. Pero otro fenómeno similar se manifestaba en lo que analizaremos en las siguientes páginas; esto es, en la reiterada proyección que disfrutó en la nueva era democrática el lenguaje plástico de los artistas vascos que a partir de la década de los cincuenta habían alcanzado éxito nacional e internacional. Hablamos de la abstracción geométrica y principalmente escultórica que caracterizó la obra de algunos integrantes del colectivo Gaur, el subgrupo guipuzcoano del Movimiento de la Escuela Vasca creado en $1966^{14}$.

Figura 1: Cartel del Aberri eguna celebrado en Vitoria-Gasteiz el 10 de abril, s/f.

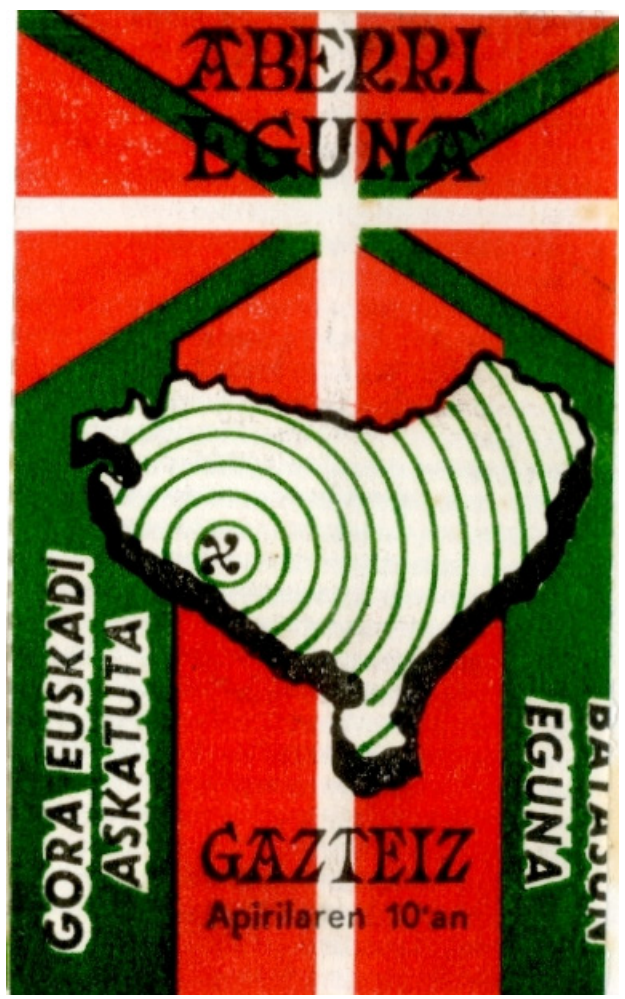

Fuente: Base de datos de pegatinas de la transición política española. Fundación Sancho el Sabio.

Efectivamente, a partir de 1975 los antiguos integrantes del colectivo realizaron innumerables diseños y logotipos para organismos e iniciativas relevantes de la sociedad

\footnotetext{
${ }^{13}$ Järlehed, Johan, "La letra vasca. Tradición inventada, nacionalismo y mercantilización en el paisaje lingüístico en Euskal Herria", en Fernández Ulloa, Teresa (ed.), Ideology, Politics and Demands in Spanish Language, Literature and Film, Cambridge, Cambridge Scholars Publishing, 2012, pp. 334-357.

${ }^{14}$ El Movimiento de la Escuela Vasca fue un intento colectivo por fomentar la socialización del arte en la vida cultural vasca. Organizado en un principio por Jorge Oteiza y Agustín Ibarrola, se articuló en cuatro grupos: Gaur, Emen, Orain y Danok, uno por cada provincia. Entre ellos, el colectivo guipuzcoano Gaur estuvo integrado por Amable Arias, Rafael Ruiz Balerdi, Nestor Basterretxea, Eduardo Chillida, Remigio Mendiburu, Jorge Oteiza, Antonio Sistiaga y José Luis Zumeta. Su actividad finalizó en 1969.
} 
vasca $^{15}$. Entre otros, el logo por la defensa de una Costa Vasca No Nuclear (fig. 2.) y la Amnistía Internacional, Eusko Ikaskuntza ${ }^{16}$, el del partido político EIA (fig. 3), el del movimiento Bai Euskerari $^{17}$, el de la Universidad del País Vasco ${ }^{18}$, el del Parlamento Vasco ${ }^{19}$ y, más adelante, el del Banco Kutxa ${ }^{20}$, el Orfeón ${ }^{21}$ o la Asociación de Amigos del Bertsolarismo ${ }^{22}$. Asimismo, mediante adquisiciones o encargos de los diferentes municipios, diputaciones o del mismo Gobierno Vasco, se fueron sumando multitud de esculturas de estos mismos autores en los espacios públicos de todo el territorio, siendo la mayoría de ellas construidas en una escala aumentada de la obra original ${ }^{23}$. Las calles, plazas, parques o miradores de las ciudades y pueblos, las carreteras principales de la comunidad autonómica o los lugares históricamente simbólicos, como fue el caso de la villa foral de Guernica donde se ubicó el monumento Gure aitaren etxean/En la casa de nuestro padre (fig. 4.), se vistieron con esta nueva seña de identidad. Por lo tanto, la intervención artística en el espacio comunitario - la cual llegaría a interpelar también la esfera privada, como ocurría con el calendario de Caja Laboral de 1986, ilustrado con las esculturas más famosas de estos artistas - desembocaría en que dicho imaginario plástico pasara a interiorizarse como una representación identitaria de la nueva era política de Euskadi.

\footnotetext{
${ }^{15}$ Para más información en torno a la cultura visual y las aportaciones gráficas de estos autores en la década de los setenta consultar: Golvano, Fernando, Disidencias otras: poéticas y acciones artísticas en la transición política vasca: 1972-1982, San Sebastián, Diputación Foral de Gipuzkoa, 2005; y Golvano, Fernando (comis.), Laboratorios 70. Poéticas/Políticas y crisis de la modernidad en el contexto vasco, catálogo de exposición (Bilbao, Sala Rekalde, del 14 de mayo al 6 de septiembre de 2009), Bilbao, 2009.

${ }^{16}$ Eduardo Chillida, 1978.

${ }^{17}$ Nestor Basterretxea, 1978.

${ }^{18}$ Eduardo Chillida, 1982. En 2013 la Universidad crearía una fuente tipográfica corporativa basada en este logotipo y en el mensaje que venía a representar: Eman ta zabal zazu, "Dalo y difúndelo".

${ }^{19}$ Nestor Basterretxea, 1983.

${ }^{20}$ Eduardo Chillida, 1990.

${ }^{21}$ Eduardo Chillida, 1992.

${ }^{22}$ La traducción de Bertsozale Elkartea. Jorge Oteiza, 1996.

${ }^{23}$ Entre otros muchos ejemplos: Herri txistu otza (R. Mendiburu, 1975, San Sebastián, encargo privado), El peine de los vientos (E. Chillida, 1976, San Sebastián, donación del autor al municipio), Ruido del abismo y Viento del abismo (R. Mendiburu, 1977, San Sebastián, Caja de Ahorros de Guipúzcoa). También proyectos de urbanismo o arquitectura como la Plaza Floral de Vitoria-Gasteiz (participación de E. Chillida, 1979, VitoriaGasteiz, Diputación Foral de Álava), La paloma de la paz (N. Basterretxea, 1988, San Sebastián, Ayuntamiento de San Sebastián), Bizkaia. Una ola de hierro (N. Basterretxea, 1989, Leioa-Getxo. Diputación Foral de Vizcaya), Homenaje a Fleming (E. Chillida, 1990, San Sebastián, Ayuntamiento de San Sebastián), Elogio del hierro III (E. Chillida, 1991, Bilbao, BBV), la decoración en el embalse Arriaran (N. Basterretxea, 1994, Beasain, Diputación Provincial de Guipúzcoa), La libertad se abre redonda (N. Basterretxea, 1994, Vitoria-Gasteiz, donación del autor al municipio), La cruz de la paz (E. Chillida, 1997, San Sebastián, donación del autor a la Catedral del Buen Pastor del municipio), Txopitea eta bakea (J. Oteiza, 1998, Eibar, Ayuntamiento de Éibar), La piedad (J. Oteiza, 1999, San Sebastián, Ayuntamiento de San Sebastián), Homenaje a bertsolari (J. Oteiza, 1999, Zarauz, Gobierno Vasco) o Mi siesta (J. Oteiza, 1999, Zarauz, donación del artista a Joseba Gárate).
} 
Figura 2: Logotipo de Eduardo Chillida para la Comisión de Defensa por una Costa Vasca no Nuclear, 1976.

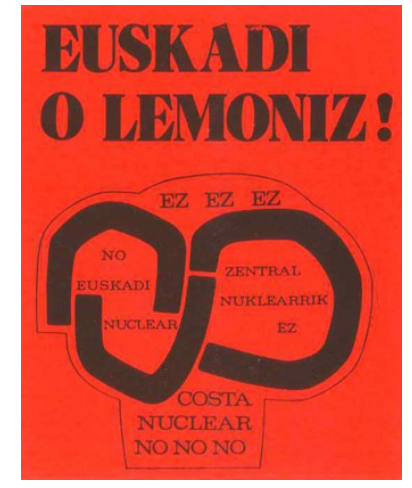

Fuente: Base de datos de pegatinas de la transición política española. Fundación Sancho el Sabio.

Figura 3: Logotipo de Jorge Oteiza para el partido político EIA, Euskal Iraultzarako Alderdia. 1977.
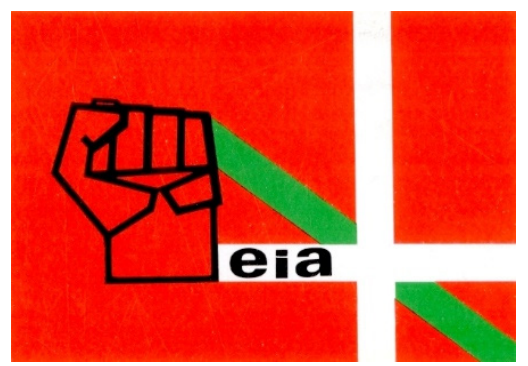

Fuente: Base de datos de pegatinas de la transición española. Fundación Sancho el Sabio.

Figura 4: Eduardo Chillida, Gure aitaren etxean/ "En la casa de nuestro padre", 1988, Guernica. Encargo del Gobierno Vasco.

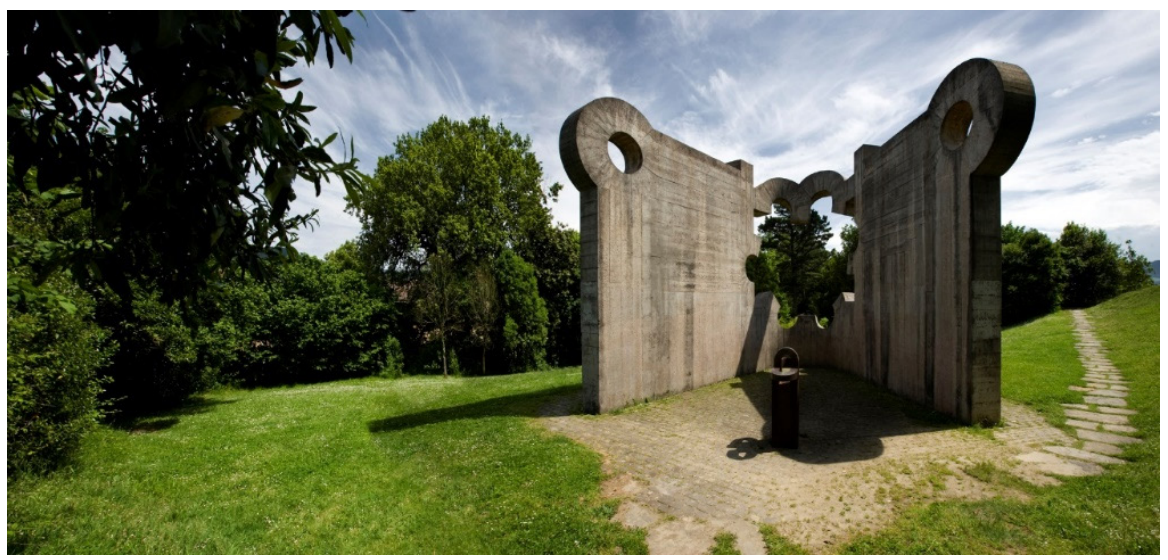

Fuente digital.

Aplicando una lectura gramsciana a este fenómeno, la hipótesis que se plantea en las siguientes páginas es que este proceso de difusión y, por consecuente, su asimilación por parte de la ciudadanía vasca, guarda relación con el discurso político defendido por el PNV en las 
primeras décadas de la reinstauración de la democracia, así como con la evolución de sus directrices en las siguientes décadas ${ }^{24}$. De esta forma, se pondrá en entredicho el relato que ha mantenido la historia del arte vasco del siglo xx en torno a que fue la capacidad de la propia expresión artística — la autonomía del arte — o la genialidad y el "buen ojo" de estos artistas lo que llevó a que la comunidad vasca hiciera suyo o se identificara con este lenguaje. Se propone, por tanto, un cuestionamiento de la coyuntura en la que se basa la memoria artística postfranquista del País Vasco.

\section{Arte oficialista: tradición y modernidad}

La instrumentalización del hecho cultural no fue un caso aislado del contexto vasco, sino al contrario, fue una de las características del panorama político que atravesó el estado español en los años de transición. En el marco estatal, como ha sido analizado por Giulia Quaggio, el nuevo gobierno socialista presentó el campo de la cultura y las artes como la máxima expresión de la esencia democrática. El bien compartido que simbolizaba la cultura se convertía en la oportunidad idónea para que los y las ciudadanas recuperaran la escena pública y sus derechos civiles hasta entonces arrebatados ${ }^{25}$. Pero, además, esta nueva articulación de la noción de cultura posibilitaba la reconstrucción de una nueva identidad democrática. Una identidad "mejorada" que permitía diferenciarse de aquella España franquista, atrasada, culturalmente aislada y "diferente" del resto de Europa ${ }^{26}$. Por ende, esta misma mirada hacia el campo de la cultura y la defensa del arte se vio repetida en diversos puntos del país y especialmente en las regiones que, como el País Vasco o Cataluña, abogaban por las políticas nacionalistas, la esfera cultural funcionó como margen de acción o, en palabras de Jorge Marzo y Tere Badia, como “caballo de Troya" para la construcción de visualidades identitarias ${ }^{27}$.

Al igual que ocurría en el gobierno central y aunque viniera a satisfacer diferentes necesidades, el papel que jugó la cultura en el discurso político del PNV de la transición fue vital. En primer lugar, el partido jertzale tuvo que enfrentase a la urgente necesidad de superar

\footnotetext{
${ }^{24}$ Desde la reorganización del Gobierno Vasco, quienes han ocupado el puesto de Consejeros de Cultura han sido: José Antonio Maturana (PSE, 1978-1979), Ángel Olarte (PNV, 1979-1980), Ramón Labayen (PNV, 1980-1984), Joseba Arregi (PNV, 1984-1985), Luis María Bandrés (PNV, 1985-1987), Joseba Arregi (PNV, 1987-1995), María del Carmen Garmendia (PNV, 1995-2001), Miren Azkarate (PNV, 2001-2009), Blanca Urgell (PSE-EE, 20092012), Cristina Uriarte (PNV, 2012-2016), Bingen Zupiria (PNV, 2016-2020).

${ }^{25}$ Quaggio, Giulia, "Política cultural y transición a la democracia: el caso del Ministerio de Cultura UCD (19771982)", en Historia del presente, 17 (2011), pp. 109-125.

${ }^{26}$ Marzo, Jorge Luis, "Lo moderno como antimoderno. Apuntes sobre el arte oficialista español en la época de la Transición", en VV.AA., La imagen del poder, el poder de la imagen, Salamanca, Universidad de Salamanca, 2013, pp. 199-218.

${ }^{27}$ Marzo, Jorge Luis y Badia, Tere, "Las políticas culturales en el Estado Español (1985-2005)”. Material disponible en: www.soymenos.net/politica espanya.pdf.
} 
y sustituir el parámetro racista y esencialista de la doctrina identitaria de Sabino Arana ${ }^{28}$. Como nueva respuesta, el partido reformuló este planteamiento por medio de la convicción de que aquello que realmente marcaba y diferenciaba a la nación vasca —en términos del partido el "pueblo vasco" - era la cultura compartida. De esta forma, la identidad nacional, el fundamento principal de la expresión nacionalista, pasaba a sustentarse sobre un parámetro inclusivo ${ }^{29}$. Se repetía, por tanto, la vinculación entre la cultura y la esencia democrática, por compartir ambas la aspiración de representar la participación voluntaria y plural, la soberanía compartida y la igualdad de derechos.

No obstante, si la cultura era aquello que determinaba para el PNV la identidad vasca, esta obligatoriamente estaría relacionada con su origen histórico. Ya desde el discurso sabiniano clásico, el pasado era lo que daba forma a la comunidad vasca y, a su vez, aquello que enlazaba la sociedad con las aspiraciones presentes y futuras ${ }^{30}$. Por ello, la recuperación y actualización del legado histórico-cultural se presentó como una urgencia colectiva del nuevo panorama sociopolítico. Gracias a esta recuperación del pasado, se certificaba la existencia de un pueblo vasco que guardara características históricas, lingüísticas y culturales propias, a la vez que se preservaba su continuidad. Pero, además, la reanimación de este legado facilitaba la tarea de definir cuáles eran los rasgos propios que compartían los y las integrantes de esta comunidad ${ }^{31}$. En la práctica, como apuntaba Manuel Montero, aparte de la referencia al euskera, el partido jertzale no dictó mayores concreciones sobre los elementos que constituían la cultura vasca, sino que esta se configuraba en negativo, en contraposición al "otro". La forma en que se manifestó esta premisa, como veremos también en el caso de la representación artística, fue a través de una especie de depuración interna, acentuando aquellos rasgos identitarios que estaban consensuados como propios y eliminando los que no lo eran ${ }^{32}$. Por otro lado, en relación con el panorama político, esta centralidad por la defensa de la recuperación del legado históricocultural facilitó que el PNV se presentara con una imagen distinguida de cara a la nueva etapa política: ser la fuerza política de continuación democrática, ligada siempre a su faceta antifranquista y compatriota del pasado republicano. Con ello, además de dotar de credibilidad al bando, se agregaba una cualidad distintiva frente a los jóvenes partidos que como Euskadiko Ezkerra o Herri Batasuna fueron emergiendo en el contexto político vasco de la transición ${ }^{33}$. La recuperación del pasado cultural, por tanto, funcionó como herramienta de gobernanza; como medio de acción para el ejercicio de soberanía nacional y la autodeterminación, por un lado, y

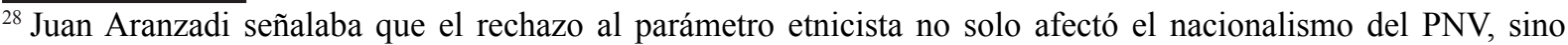
también las teorizaciones de ETA. Aranzadi, Juan, Mileniarismo vasco. Edad de Oro, etnia y nativismo, Madrid, Taurus, 2000 (año de publicación del libro original 1981), p. 555.

${ }^{29}$ Montero, Manuel, "La reformulación identitaria del nacionalismo vasco. La ideología del PNV tras la dictadura franquista", en Historia Actual Online, 38, 3, (2015), pp. 7-21.

${ }^{30}$ Landaberea, Eider, Los “nosotros" en la transición. Memoria e identidad en las cuatro principales culturas politicas del País Vasco (1975-1980), Madrid, Editorial Tecnos, 2016, p. 71.

${ }^{31}$ Arrieta Alberdi, Leyre, "Por los derechos... op. cit.

${ }^{32}$ Montero, Manuel, "La reformulación... op. cit.

${ }^{33}$ Arrieta Alberdi, Leyre, "Por los derechos... op. cit.
} 
como canal para que los individuos de la comunidad interiorizaran los discursos del poder, por el otro.

En relación con el cruce entre las políticas culturales y la proyección artística, decíamos que la forma en que se articuló esta unión en Euskadi fue diferente a la vía trazada por el gobierno socialista. Mientras que para el gobierno central "la idea de una cultura 'moderna' no se conjugaba con la palabra 'vanguardia' por ser esta demasiado vieja, demasiado militante" 34 , siendo ejemplo de ello la popularización mediática de la Movida madrileña ${ }^{35}$, para las autoridades vascas la imagen de la nueva era se configuraba a la inversa. La imagen plástica que viniera a representar la nueva era democrática debía integrar los principios básicos del discurso nacionalista entre fusionar una imagen actualizada, abierta y moderna de la sociedad y la cultura vasca, a la vez que se hacía referencia a su raíz histórica. Principios que se encontraban en el proyecto artístico del citado colectivo Gaur.

Ciertamente, a diferencia de los demás subgrupos que conformaron el Movimiento de la Escuela Vasca, el conjunto guipuzcoano tuvo la aspiración de generar un imaginario artístico renovado que representara la identidad vasca. Un propósito que partía de las teorías de Oteiza narradas en el libro Quousque Tandem...! Ensayo de interpretación estética del alma vasca, publicado por primera vez en $1963^{36}$. Influenciado por las teorías y la mirada militante de los trabajos de los antropólogos vascos del momento ${ }^{37}$, la obra se presentaba como un alegato en defensa del "estilo vasco"38. Así, la prehistoria, concretamente el crómlech neolítico vasco, el mundo rural y algunas manifestaciones culturales como el bertsolarismo, la pelota vasca o los deportes rurales se convertían para el escultor-teórico en referencias originarias de la cultura vasca. El autor identificaba asimismo otras características inmateriales de la expresión vasca como, por ejemplo, la contención de las emociones o la racionalidad ${ }^{39}$. Como ha sido señalado, la propuesta de Oteiza no solo influenció masivamente la comunidad artística del momento y las siguientes generaciones, sino que, su planteamiento existencialista en torno al ser estético vasco se convirtió en referente intelectual del movimiento vasco antifranquista ${ }^{40}$. El hecho de que para 1983 el libro contase con cuatro ediciones pone de manifiesto la importancia que adquirió la obra en el contexto social al que nos referimos. Por todo ello, las formas plásticas vinculadas a esta propuesta teórica e ideológica, como fueron las esculturas abstractas-geométricas realizadas en

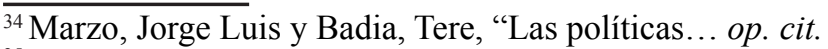

${ }^{35}$ Para más información sobre la instrumentalización de la Movida madrileña consultar: Carmona, Pablo, "La pasión capturada. Del carnaval underground a La Movida madrileña marca encarnada", en Pedro G. Romero (ed.), Desacuerdos 5, Barcelona, Granada, San Sebastián, Sevilla, MACBA, Centro José Guerrero, Arteleku, UNIA, 2009, pp. 147-158.

${ }^{36}$ Oteiza, Jorge, Quousque tandem...! Ensayo de interpretación estética del alma vasca. Reimpr. Vega, Amador (coord.), Alzuza, Fundación Museo Jorge Oteiza, 2007 (año de publicación del libro original, 1963).

${ }^{37}$ Zulaika, Joseba, "Un americano entre los vascos", prólogo a Douglas, William A., Muerte en Murélaga, Irún, Alga, 2003 (año de publicación del libro original 1973), p. 5.

38 "En este libro se trata de cuál es y cómo ese estilo vasco", Oteiza, Jorge, Quousque..., op. cit., p. 102.

39 "Baroja es el ejemplo más limpio y entero de hombre en tradición de estilo vasco. Estilo vasco quiere decir privación de un sentimiento". Ibidem, p. 243.

${ }^{40}$ Martínez Gorriarán, Carlos, Jorge Oteiza, hacedor de vacíos, Madrid, Marcial Pons, Ediciones de Historia, 2011, pp. $250-251$.
} 
hierro, roble o bronce y que tomaban como referencias - muchas veces siendo visible en los títulos - del legado prehistórico, mitológico o rural y asociadas mediante convenciones a las construcciones culturales del carácter vasco como la seriedad y la racionalización, se convertían en ejemplos del buscado "estilo vasco". Así pues, los trabajos de Eduardo Chillida, Remigio Mendiburu, Vicente Larrea o Nestor Basterretxea, especialmente elocuente este último en su Serie Cosmogónica Vasca donde trató de reinterpretar las diferentes deidades de la mitología vasca (fig. 5), fueron asumidos en su contexto con la renovación ideológica, el apoyo a la cultura vasca y la oposición a la dictadura.

Figura 5: Nestor Basterretxea. Intxisu. Parte de la Serie Cosmogónica Vasca, 1972.

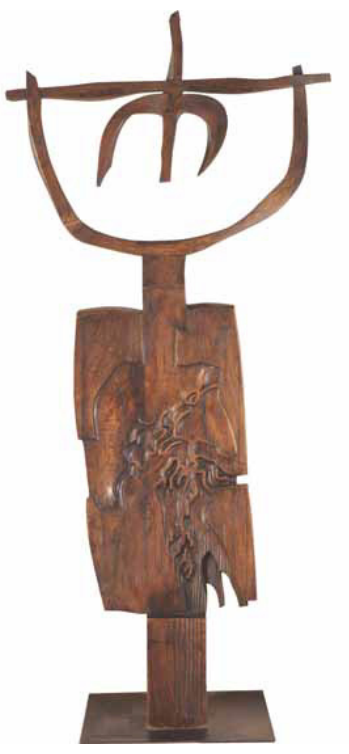

Fuente: Museo de Bellas Artes de Bilbao.

Junto a la apropiación de estos valores, otras características formales de este "estilo vasco" lograban satisfacer las necesidades políticas del PNV de la transición. En primer lugar, las lecturas esteticistas que acompañaron las obras de Chillida, Oteiza o Basterretxea en el marco estatal e internacional desde la década de los cincuenta favorecieron que su plástica se percibiera como un lenguaje abierto a interpretaciones que, además, lograba vincular lo local con lo universal ${ }^{41}$. Por tanto, la plástica respondía al discurso identitario del PNV: todo aquel que quisiera verse reflejado en este imaginario cultural vasco, tendría opción a ello. Y, al mismo tiempo, lograba atender la aspiración política de los organismos vascos en su afán de proyectarse hacia el marco internacional, principalmente a Europa. Ciertamente, la voluntad de participar en las dinámicas europeas fue una constante para el PNV, pues la naturaleza plurinacional del proyecto de la Unión Europa, bajo el lema de "la Europa de los pueblos", permitía al País

\footnotetext{
${ }^{41}$ Peio Aguirre reflexionaba sobre este parámetro destacando cómo, por ejemplo, Jorge Oteiza y Edaurdo Chillida fueron premiados con el premio "Vasco Universal", en reconocimiento a su condición de personajes "universales". Aguirre, Peio, "Euskal Teknika - Técnica Vasca", en MMIV Gure Artea, Bilbao, País Vasco. Servicio Central de Publicaciones, 2004, pp. 10-31.
} 
Vasco encontrar un nuevo espacio de diálogo para sus aspiraciones nacionalistas. Esta unión de lo local con lo universal, por ejemplo, fue textualmente el mensaje que vino a transmitir el logotipo que diseñó Eduardo Chillida para el Banco Kutxa ${ }^{42}$.

Ahora bien, aun abierta a diferentes explicaciones, esta expresión plástica lograba visibilizar un determinado imaginario de la cultura vasca. Por un lado, como analizaba José Ignacio Homobono, la visión patrimonial generalizada desde las autoridades vascas, visible en el caso de estudio, ha remitido históricamente al folclore, a lo rural o lo prehistórico, ignorando, por su parte, otras facetas de la cultura como lo urbano o lo industrial, las cuales habrían sido contaminadas por costumbres procedentes de fuera de Euskadi ${ }^{43}$. Por otro lado, como decíamos antes, esta representación artística de la cultura vasca tomaba forma contra aquello que no era, en este caso, frente al "otro" español. La identidad vasca, ligada al carácter frío, norteño y a características como la seriedad, la racionalidad o la dureza, tomaba cuerpo en contraposición a la expresión estereotipada del mundo español, vinculándose este a ideales como la pasión, el ruido, el color, la herencia barroca ${ }^{44}$ o incluso la feminidad ${ }^{45}$. En definitiva, la insistente proyección que disfrutó en democracia el imaginario identificado a partir de los años sesenta como el "estilo vasco" vendría a ser síntoma de una determinada construcción social que como tal, trataba de establecer una narrativa y una cohesión social a la vez que legitimar una determinada autoridad ${ }^{46}$.

\section{Un pueblo intérprete}

Indicios del éxito que ha disfrutado hasta la actualidad esta construcción en torno a la representación artística de la cultura vasca, lo encontramos en las interpretaciones que se han generado en torno a la pregunta de cómo se interiorizó este imaginario artístico en la sociedad vasca. En líneas generales, entre estas reflexiones subyacen repetidamente dos ideas: a) Que el fenómeno de que a partir de los años setenta la sociedad vasca asimilara este imaginario como algo en lo que se veía reflejada radicaba en el acierto o en la capacidad de estos artífices

\footnotetext{
${ }^{42}$ P. A., "Adiós al anagrama de Chillida, en El Diario Vasco, 13 de noviembre de 2008. «https://www.diariovasco. com/20081113/economia/adios-anagrama-chillida-20081113.html» [Consultado el 25 de enero de 2020].

${ }^{43}$ Homobono, José Ignacio, "Del patrimonio cultural al industrial: una mirada socioantropológica", en Pereiro, Xerardo; Prado, Santiago y Takenaka, Hiroko (eds.), Patrimonios culturales, educación e interpretación. Cruzando límites y produciendo alternativas, Donostia-San Sebastián, Ankulegi Antropologia Elkartea, 2008, pp. 57-74.

${ }^{44}$ Sobre la construcción histórica en torno a la identidad hispánica y el barroco ver: Marzo, Jorge Luis, La memoria administrada, Madrid-Buenos Aires, Katz Editores, 2010.

${ }^{45}$ Pese a sobrepasar los límites de este estudio, cabe destacar que la diferencia sexual tuvo un papel central en la reconstrucción del nacionalismo vasco. Aunque se ajuste a una cronología anterior al del presente estudio, se recomienda consultar: Aresti, Nerea, "El gentleman y el bárbaro. Masculinidad y civilización en el nacionalismo vasco (1893-1937)", en Cuadernos de Historia Contemporánea, 39 (2017), pp. 83-103.

${ }^{46}$ Hobsbawm, Eric y Ranger, Terence, Tradición inventada, Zaragoza, Titivillus, edición digital, 2018 (año de publicación del libro original 1983), pp. 17-22.
} 
de dar forma a esa necesidad colectiva; y b) Que el hecho de que dicho imaginario artístico se institucionalizara repercutió en que con el tiempo la carga significativa de esta expresión se vaciara. En este caso, partimos de la premisa de que ambas interpretaciones son parte y consecuencia de la asimilación del relato generado en torno a la historia del arte vasco de la segunda mitad del siglo xx.

A la hora de reflexionar sobre la buena acogida de esta nueva tradición plástica, una de las razones que explica este fenómeno radica en que la instauración no fue percibida como un elemento impuesto desde el discurso político, sino como una manifestación que provenía del ámbito popular. Y es que en el mismo marco en el que se inició este respaldo institucional a los artistas que en los años de dictadura se habían posicionado a favor de la cultura vasca y habían logrado un reconocimiento a nivel internacional, mantuvieron, aunque con posiciones e ideologías diversas ${ }^{47}$, una relación muy directa con los movimientos sociales y políticos, así como directamente con el nuevo Gobierno Vasco. Por ejemplo, el mismo círculo de artistas se reunió en 1979 con el Consejero de Cultura para discutir en torno a la "euskaldunización" de la Facultad de Bellas Artes de Bilbao; por su parte Jorge Oteiza siguió realizando públicamente peticiones y duras críticas a los organismos públicos vascos ${ }^{48}$; y, por otro lado, Ramón Labayen, el Consejero de Cultura entre 1980-1983, nombró como asesor artístico a Nestor Basterretxea, cargo que mantuvo por dos años ${ }^{49}$. A esto se sumaba que estos artistas hubieran participado en las iniciativas artísticas de cariz popular y nacionalista que habían emergido desde principios de los años setenta ${ }^{50}$ y que realizaran diseños y logotipos a favor de diferentes movimientos populares. Así pues, apoyándonos en las palabras de Txomin Badiola, podría decirse que aquellos artistas que en las décadas precedentes fueron productores del "estilo vasco", encarnaron diferentes roles en la sociedad vasca de los años ochenta. Jorge Oteiza se convirtió en el artista mitificado o "profeta", especialmente para los artistas de las siguientes generaciones, Eduardo Chillida representó al escultor internacional que a su vez colaboraba con las buenas causas sociales y, por su parte, Nestor Basterretxea encarnó la figura del creador aplicado y práctico que había encontrado su lugar en la nueva institución vasca ${ }^{51}$.

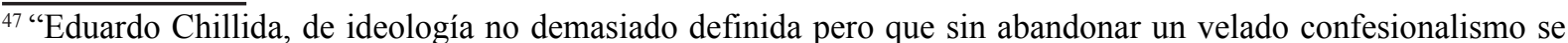
inscribe a caballo entre el nacionalismo y el abertzalismo, y Nestor Basterretxea, simpatizante y sentimentalmente ligado al Partido Nacionalista Vasco" en Guasch, Ana María, Arte e ideología en el País Vasco: 1940-1980, Madrid, Ediciones Akal, 1985, p. 150. Por su parte, Jorge Oteiza en 1977 se presentó como candidato al Senado con el partido Euskadiko Ezkerra.

${ }^{48}$ Véase: Unzueta, Patxo, "Las críticas de Oteiza a la cultura y al nacionalismo vasco originan una dura polémica en Euskadi”, en El País, 11 de febrero de 1985. «https://elpais.com/diario/1985/02/11/cultura/476924409 850215. html» [Consultado el 27 de julio de 2020].

${ }^{49}$ Vadillo Eguino, Miren, "Transformaciones... op. cit.

${ }^{50}$ Para más información sobre estas actividades artísticas consultar: Vadillo Eguino, Miren, "El carácter identitario de las iniciativas artísticas populares en el País Vasco durante los años setenta", en ASRI. Arte y Sociedad. Revista de Investigación, 16 (2019), pp. 163-177.

${ }^{51}$ Badiola, Txomin, "The Site for Controversy: The Case of 1980s New Basque Sculpture, from Roots to Rhizomes", en Bray, Zoe (ed.), Beyond Guernica and the Guggenheim. Art and Politics from a Comparative Perspective, Reno, University of Nevada 2015, pp. 81-90.
} 
Así, frente al enemigo común que suponía la superación definitiva de todo el aparato franquista a favor de la construcción de una nueva sociedad vasca, unida a la rapidez que caracterizó este proceso, la imagen institucional pasó a difuminarse con la expresión de lo popular. Si la posición de deseo es lo que sostiene todo sistema social ${ }^{52}$, podría decirse que, en el caso vasco, los diferentes agentes y las energías que participaron en este proceso - tanto institucionales, populares, como individuales o colectivos - se fusionaron. Este fenómeno, como decíamos antes, nos lleva a considerar el campo de la cultura a partir de los planteamientos gramscianos, entendiendo que este, lejos de representar un poder homogéneo, constituye un espacio de lucha donde las diversas fuerzas pugnan entre sí por la hegemonía. Este punto de vista permite, por tanto, explicar cómo con la llegada de la democracia y la defensa institucionalizada del nacionalismo vasco, los esfuerzos populares de carácter disidente o contracultural buscaron alcanzar los espacios públicos y representativos de la comunidad y, a su vez, los poderes institucionales trataron de hacerse con las energías renovadoras de la esfera popular. Por todo ello, el lenguaje artístico abstracto-geométrico-escultórico que había sido generado ya en los años cincuenta se asumió como un lenguaje moderno, no anticuado, siendo así naturalizado por la sociedad, en palabras de Beatriz Herráez, como "el imaginario del cambio" ${ }^{53}$.

\section{El éxito de una historia}

A lo largo de estas páginas hemos insistido en la imposibilidad de desvincular la difusión de este imaginario artístico con el proceso de configuración de la historia del arte del País Vasco posterior a la Guerra Civil. Y es que ambos fenómenos son fruto y testimonio de una misma construcción. Ahora bien, ¿quiénes tuvieron la agencia para generar la narración? y ¿bajo qué parámetros se interpretó la producción artística que se había desarrollado en el territorio en las últimas décadas? Para esta aproximación, partimos de la reflexión que lanzaba Noemí de Haro al estudiar el contexto estatal, esto es, en cómo "pensar el relato aceptado no como una mera descripción de lo sucedido sino como una representación histórica que tiene una cierta funcionalidad arroja nueva luz sobre la narración aceptada" ${ }^{54}$.

Un factor determinante en el inicio de este proceso fue el hecho de que, a partir de 1975, el mundo de las editoriales y los periódicos autonómicos vascos vivió un gran auge, factor que

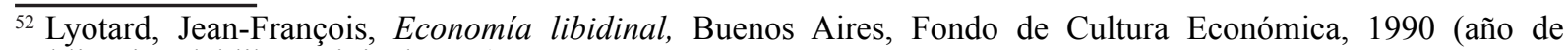
publicación del libro original 1974), pp. 19-20.

${ }^{53}$ Herráez, Beatriz, "Arte y crítica durante la Transición en el País Vasco", en Desacuerdos 8, Barcelona, Granada, Madrid, Sevilla, MACBA, Centro José Guerrero-Diputación de Granada, MNCARS, UNIA, 2014, pp. 114-147.

${ }^{54}$ De Haro García, Noemí, "La historia del arte español de la transición: consecuencias políticas de una representación”, en Albarrán, Juan (coord.), Art nsición, tra nsición: arte y transición, $2^{a}$ edición revisada y ampliada, Madrid, Brumaria, 2018, pp. 595-633.
} 
posibilitó la creación de nuevos espacios para la escritura interesada en las propuestas artísticas contemporáneas de la región o en su historia. En estos medios comenzaron a escribir una nueva generación de especialistas en arte contemporáneo que, en líneas generales, por haberse formado obligatoriamente fuera del País Vasco, recibieron claras influencias de las perspectivas sociológicas y marxistas que marcaron la historiografía y la crítica de arte generada en otros puntos del estado a partir de los años sesenta ${ }^{55}$. A este punto de vista generalizado, se sumaba la mirada nacionalista dominante en el clima regional de la época ${ }^{56}$, así como otra característica señalada por Herráez, esto es, que en la crítica de arte de la transición en el País Vasco fueron los propios artistas protagonistas de esta historia en desarrollo quienes produjeron gran parte de este corpus de escritura ${ }^{57}$. Esto repercutió en que, junto a las demás perspectivas, se sumara la influencia del estilo de escritura filosófico-antropológico de Oteiza ${ }^{58}$, pero también, en que los mismos actores legitimaran su posición en el relato.

Por lo tanto, el cruce entre los diferentes factores y los requerimientos que venían a satisfacer determinó que la narración que comenzaba a generarse en torno a la historia del arte del País Vasco de las últimas décadas se centrara en aquellos artistas y propuestas que habían manifestado una actitud disidente contra el Régimen de Franco y/o a favor del nacionalismo vasco. En consecuencia, los ejes vertebradores de la historia del arte del País Vasco de la segunda mitad del siglo xx pasaban a ser el proyecto de la Basílica de Aránzazu y las agrupaciones de Equipo 57, Estampa Popular de Vizcaya y, principalmente, el Movimiento de la Escuela Vasca. Al igual, Jorge Oteiza, Eduardo Chillida, Agustín Ibarrola, Nestor Basterretxea o Remigio Mendiburu se convertían en los principales actores del relato y, por su parte, los Encuentros de Pamplona 72 encarnaron el cierre de una época.

Por otra parte, por el contexto en el que surge, la construcción del relato se nutrió de las diferentes interpretaciones que habían recibido los artistas y sus obras desde sus inicios. Por un lado, se repetían algunas de las interpretaciones distintivas de la crítica de los años cincuenta como, por ejemplo, la interpretación esteticista de la abstracción y su vinculación con la idea de modernidad, progreso o incluso intelectualidad, basada esta última en la aparente necesidad de justificar las obras con un corpus teórico ${ }^{59}$. Pero a estas capas interpretativas se añadían aquellas

\footnotetext{
${ }^{55}$ Ana María Guasch, Xabier Sáenz de Gorbea o Francisco Javier San Martín serían ejemplo de esta nueva generación de historiadores y críticos de arte:

${ }_{56}^{5}$ Dentro de esta tendencia destacamos los nombres de Edorta Kortadi y Juan Plazaola. Pese a pertenecer a generaciones diferentes y trabajar en medios diferentes, ambos autores abogaron desde el tardofranquismo por la mirada abertzale en sus escritos sobre la cultura y el arte del territorio.

${ }^{57}$ Herráez, Beatriz, “Arte y... op. cit.

${ }^{58}$ En esta línea entrarían los escritos de Pedro Manterola y, más tarde, los de Fernando Golvano. Sin embargo, fundamentalmente por el carácter izquierdista que compartían las diferentes miradas, en muchas ocasiones resulta complicado etiquetar los escritos de la época en una sola tendencia. Para más información, consultar: Lekuona, Ane, “'Entrada denegada'. Revisión feminista de la crítica y escritura del arte del tardofranquismo y la Transición en el País Vasco", en E. Ma . Ramos Frendo (dir) Géneros y subjetividades en las prácticas artísticas contemporáneas, Sevilla, Arcibel editores, 2020, pp. 352-365.

${ }^{59}$ Sobre la acogida de la abstracción por parte de la crítica del arte del estado español en los años del franquismo, consultar: Díaz Sánchez, Julián, La idea de arte abstracto en la España de Franco, Madrid, Ediciones Cátedra, 2013 .
} 
provenientes del giro sociológico y las inercias nacionalistas. Influidas por las explicaciones antropológicas de Oteiza, estas últimas trataron de reforzar la vinculación entre la identidad vasca y aquellas características formales que habían sido identificadas con el "estilo vasco", recurriendo para ello a argumentos esencialistas, pero también etnicistas y machistas. Por ejemplo, numerosos autores coincidían en identificar la escultura, la abstracción, los colores oscuros o la inclinación hacía la geometría como constantes históricos de la expresión vasca, justificando estos resultados con la inercia natural del "hombre vasco" hacia estas formas ${ }^{60}$. Al igual, las interpretaciones destinadas a ensalzar la plástica y el trabajo de sus autores, como era la insistencia de su fuerza física y mental o la prevalencia de la racionalidad sobre lo pasional, eran argumentos tradicionalmente empleados para privilegiar el imaginario masculino ${ }^{61}$.

No obstante, para la consolidación de este consenso narrativo sobre el pasado artístico de la región, además de la crítica del arte fue necesario que entraran en juego otros agentes legitimadores como, por ejemplo, que el arte contemporáneo vasco irrumpiera como tema de investigación dentro del mundo académico que comenzaba a florecer o que los museos más reconocidos del territorio, pero también las instituciones culturales públicas siguieran esta misma dirección a través de sus discursos expositivos y sus criterios de compra ${ }^{62}$. La ininterrumpida visualización que siguió disfrutando el citado imaginario artístico en los espacios compartidos, de nuevo, sería ejemplo de la instauración de esta narrativa. Del mismo modo, centros como la Facultad de Bellas Artes de Leioa, el centro Arteleku o La Alhóndiga jugaron un papel intermediario pero central en la transmisión de dicha narrativa a las siguientes generaciones de $\operatorname{artistas}^{63}$. Más aún, la simultaneidad y rapidez que caracteriza tal proceso repercutió en que, en muchos casos, fueran las mismas personas quienes dirigieron o formaron parte de los diferentes campos de actuación ${ }^{64}$. En consecuencia, la forma en que se elaboró y se legitimó la historia

\footnotetext{
${ }^{60}$ Ejemplos visibles en los siguientes textos: Mirantes, Fernando, "Mi problema investigativo". Conferencia impartida en Exposición de Arte Vasco, catálogo de la exposición (Baracaldo, diciembre 1971-enero 1972), Baracaldo, s/p.; Plazaola, Juan, "La escuela vasca de escultura", en VV.AA, Cultura Vasca, II, San Sebastián, Erein, 1978, p. 331-355.; VV.AA., Arte Vasco y Euskal Artea, Tolosa, Erein, 1982, p. 182; Kortadi, Edorta (com.), Pintura vasca $=$ Euskal margogintza , catálogo de la exposición (San Sebastián, Sala de Exposiciones de la Caja de Ahorros Provincial de Guipúzcoa, 1984), San Sebastián, 1984, s/p.

${ }^{61}$ Como, por ejemplo: "Los artistas vascos son hombres de oficio, hombres de herramienta, inmediatos herederos de los herreros, fundidores, carpinteros, tallistas y canteros de nuestra larga tradición vasca". Plazaola, Juan, "La escuela...", op. cit.

${ }^{62}$ Ya en los primeros años de democracia a todos los artistas que integraron el grupo Gaur se les dedicaron gran cantidad de exposiciones individuales en los espacios más reconocidos de la región, como eran el Museo de Bellas Artes de Bilbao, el Museo San Telmo de San Sebastián o las salas de exposiciones de las diferentes Cajas de Ahorro. Por ejemplo, José Luis Zumeta en el Museo de Bellas Artes de Bilbao en 1978. También Zumeta en el Museo San Telmo de San Sebastián en 1980, Rafael Ruiz Balerdi en la Caja de Ahorros Vizcaina en Bilbao en 1980. Un año más tarde Eduardo Chillida en el Museo de Bellas Artes de Bilbao. Balerdi también en la Caja de Ahorros Provincial de Guipúzcoa en San Sebastián en 1982, o un año más tarde Remigio Mendiburu en el Museo San Telmo. En 1982, al igual, Nestor Basterretxea exhibe en la Caja de Ahorros Municipal de San Sebastián. En 1985 se proyecta una exposición antológica de Amable Arias en el Museo San Telmo. En la misma ciudad, en la Caja de Ahorros Municipal de San Sebastián en 1986 se realiza una exposición de Jorge Oteiza.

${ }^{63} \mathrm{La}$ influencia que generaron los escultores vascos más reconocidos y los principios estéticos de Jorge Oteiza fue una constante en las primeras generaciones de artistas que se formaron en los espacios citados. Algunos de ellos y ellas, como Txomin Badiola, Angel Bados, Juan Luis Moraza o Elena Mendizabal pasarían a su vez a convertirse en profesores de estos centros, continuando la legitimación de esta genealogía regional.

${ }^{64}$ Lekuona, Ane, "La historiografía del arte del País Vasco. Una revisión feminista a la segunda mitad del siglo XX”, Historia Actual Online, 51 (2020), pp. 141-152..
} 
del arte del País Vasco de la segunda mitad del siglo xx evidencia cómo los diferentes agentes con capacidad para generar un relato o una cultura de la memoria, trabajaron en la misma dirección que las autoridades vascas para que la ciudadanía asimilara los discursos del poder. Una memoria, como decíamos, basada en la lucha antifranquista y la reparación de la soberanía nacionalista.

\section{El futuro de la marca vasca}

Recordábamos que una de las ideas más repetidas entre las aproximaciones realizadas en torno a la insistente proyección que la plástica de los escultores guipuzcoanos ha vivido en las últimas décadas es que fue el proceso de institucionalización lo que llevó a la desvaloración o a la pérdida de significación del proyecto artístico originario ${ }^{65}$. Tras la revisión realizada, pensamos que esta idea tendría que ser matizada, en tanto que fue este mismo proceso el que dio pie al éxito y a la asimilación de este imaginario. No obstante, supone una lectura lógica al ver que la tendencia de emplear la plástica vinculada al círculo de escultores guipuzcoanos como signo de "lo vasco" se ha seguido manteniendo de forma constante hasta la actualidad, siendo especialmente visible en el caso de Chillida y Basterretxea. En cuanto a Oteiza habría que esperar unos años para que se diera un fenómeno similar ${ }^{66}$, pues debido al descontento del artista con el PNV, en 1985 cedió su legado al Gobierno de Navarra ${ }^{67}$. Ejemplo de este hecho son las muchas esculturas que desde los años noventa hasta la actualidad se han seguido ubicando a lo ancho del territorio ${ }^{68}$ o que el lenguaje plástico que venimos mencionando se convirtiera en atrezo de la puesta en escena de los políticos del $\mathrm{PNV}^{69}$.

\footnotetext{
${ }^{65}$ Una reflexión que ha sido trabajada principalmente desde el ámbito artístico a través de artistas como Ibon Aranberri, Asier Mendizabal y Txomin Badiola. Pero también desde la crítica del arte: Gantzarain, Xabier, Zuloa, Donostia, Elkar Argitaletxea, 2018; o Barcenilla García, Haizea, "El arte, imagen de la identidad. Mesa redonda práctica", conferencia en Meatzaleak. Material disponible en: «https://www.youtube.com/watch?v=s3DKGzVdOxc»" [Consultado el 26 de enero de 2020].

${ }^{66}$ Para "remediar" este debate, en 2007 la Diputación Foral de Gipuzkoa gastó 904.800 euros para adquirir obra del artista. Teresa Flaño, "Diputación incrementa su patrimonio de Oteiza con la compra de diez piezas", en $E l$ Diario Vasco, el 23 de junio de 2007. «https://revistas.uam.es/historiaautonoma/pages/view/normas» [Consultado el 26 de enero de 2020].

${ }^{67}$ Larrauri, Eva, "Jorge Oteiza cede todo su patrimonio a Navarra", en El País, 1 de febrero de 1992. «https://elpais. com/diario/1992/02/01/cultura/696898803 850215.html» [Consultado el 27 de julio de 2020].

${ }^{68}$ Entre otros, La fuerza de Leioa (N. Basterretxea, 2001, Leioa, Ayuntamiento de Leioa), Propósito dinámica y Construcción vacía (ambas de J. Oteiza, 2002), La variante ovoide de la desocupación de la esfera (J. Oteiza, 2002), Proposición dinámica (J. Oteiza, 2002, Leioa, Ayuntamiento de Leioa), Mirador mirando (J. Oteiza, 2003, Ayuntamiento de Leioa), Begirari IV (E. Chillida, 2003, Bilbao, Ayuntamiento de Bilbao), Homenaje a las víctimas de la guerra (N. Basterretexea, 2006, Bilbao, Gobierno Vasco), Homenaje a los primeros europeístas vascos en el día de Europa (N. Basterretxea, 2011, Vitoria-Gasteiz, Gobierno Vasco) o el cambio de ubicación de La paloma de la paz a un lugar más céntrico (N. Basterretxea, 2011, Vitoria-Gasteiz, Gobierno Vasco).

${ }^{69}$ Manterola, Ismael Manterola, "Eskultura eta pintura, politikaren ardatz", en Berriak, 14 de octubre de 2014. «https://www.berria.eus/paperekoa/1842/032/001/2014-10-14/eskultura-eta-pintura-politikaren-ardatz.amp.html»» [Consultado el 27 de julio de 2020].
} 
Si en la primera etapa democrática la proyección del "estilo vasco" vino a satisfacer una carencia representacional de la comunidad vasca, generalmente a partir de los años noventa, la difusión de este imaginario estaría relacionada con las nuevas necesidades de las autoridades vascas $^{70}$. La siguiente anécdota del escultor Txomin Badiola, situada en el año 2000, ayuda a explicar cómo incluso en el intento por homenajear hechos históricos más contemporáneos a través de obras de arte de su época, parecía existir la necesidad institucional de mantener la misma marca artística y, por tanto, una determinada construcción de la cultura y la historia vasca.

\begin{abstract}
The president [of the Basque Country] came to the point immediately: the Basque Parliament had decided to build a Monument to the Victims of Terrorism in the entrance to its headquarters in Vitoria-Gasteiz, and wished to inquire about the possibility of my accepting the commission. She told me that the Basque Parliament had decided that the monument should be made by a sculptor of the 1980s generation. The parliament was in effect seeking to encourage a generational change by means of opening up the way, on the one hand, to sculptors different from those traditionally commissioned to create monuments in the Basque Country, and on the other, to projects not necessarily linked to old formal and iconographic repertoires and traditional materials. ${ }^{71}$
\end{abstract}

Tras el declive de la industria pesada, a principios de los noventa el PNV se dispuso a enterrar dicho pasado industrial y reactivar su economía basándose en el turismo y los servicios $^{72}$, siendo la construcción del Museo Guggenheim de Bilbao, en 1992, el máximo exponente de esta reconversión a favor de las industrias culturales ${ }^{73}$. El campo de la cultura satisfizo, nuevamente, gran parte de las necesidades de las autoridades vascas, siendo inevitable que esta nueva dirección política afectara también la utilización y la funcionalidad otorgada al imaginario artístico que venimos analizado. Es decir, el lenguaje artístico ya no vendría a atender la necesidad de cohesionar una comunidad, sino a promocionar el territorio en términos del mercado.

Claro ejemplo de este uso comercial de la "marca vasca" se reflejó en la candidatura de la ciudad de San Sebastián por la Capital de Cultura Europea de 2016. Efectivamente, para el logotipo de este evento dirigido a la promoción turística se eligió de nuevo una imagen basada en un diseño preparatorio de Eduardo Chillida (fig. 7). Pero también en la programación cultural, la primera exposición que se realizó en el Museo San Telmo —el museo más reconocido y

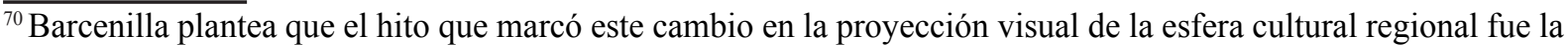
construcción del edificio del Museo Guggenheim de Bilbao. Barcenilla García, Haizea, "El arte, ... op. cit.

${ }^{71}$ Badiola, Txomin, "The Site... op. cit.

${ }^{72}$ Zallo, Ramón, Industrias y políticas culturales en España y País Vasco, Bilbao, Servicio Editorial de la Universidad del País Vasco, 1995, p. 30.

${ }^{73}$ El vínculo entre las políticas culturales y la construcción del Museo Guggenheim ha sido analizado por diferentes autores como: Zulaika, Joseba, Crónica de una seducción, Madrid, Editorial Nerea, 1997; Guasch, Ana María y Zulaika, Joseba, Aprendiendo del Guggenheim Bilbao, Madrid, Akal, 2007 o Barcenilla, Haizea, "Kultur politikak: paradigma aldaketa?", Jakin, 215-216 (2016), pp. 29-45.
} 
antiguo de la ciudad - fue 1966. Gaur Konstelazioak/2016. De modo que fue la exposición dedicada al cincuenta aniversario del grupo Gaur la que le dio la bienvenida a los más de un millón de turistas que visitaron ese año la ciudad. Del mimo modo, otras exposiciones paralelas presentaron los trabajos de este círculo de $\operatorname{artistas}^{74}$. Otra oferta que intensificaba la unión entre la ciudad y las esculturas abstractas fue la exposición al aire libre de obras del artista ingles Henry Moore. Las grandes esculturas de bronce del artista guardaban relación, principalmente, con el lenguaje plástico de Eduardo Chillida, siendo conocida también la buena relación entre los artistas, de manera que se ofreció un museo escultórico al aire libre donde las obras de los artistas "conversaban" ". Así, el caso San Sebastián 2016 evidenció cómo fundamentalmente el "icono Chillida" pasaba a convertirse en la marca turística de la ciudad" ${ }^{76}$. Efectivamente, los cada vez más recurrentes casos de este uso comercial de la herencia artística ${ }^{77}$ se convierten en ejemplo de lo que Heber Marcuse designaba con la categoría de "desublimación”. Es decir, el proceso que generan las sociedades de masas y su industria cultural haciendo que la dimensión artística se desvanezca a favor de una coexistencia pacífica en la indiferencia. $O$, en otras palabras, en cómo aquello que en su momento fue contracultural — en este caso la defensa de un proyecto artístico nacionalista en los años sesenta - va asimilando sus contenidos antagónicos, para convertirse finalmente en un arte funcional al capitalismo y reflejo del mismo ${ }^{78}$.

En definitiva, la insistente representación de este legado artístico a lo largo de las décadas nos habla de las distintas aspiraciones que las instituciones vascas tuvieron en cada época. Si en los años de la transición la esfera cultural se convirtió en el medio para satisfacer la urgencia de construir una identidad nacional renovada, con el paso de los años el legado artístico y cultural funcionó como canal para la promoción turística y la apertura del País Vasco al marco internacional. Al fin y al cabo, el caso analizado evidencia cómo mandatos tan largos como el del Partido Nacionalista Vasco en el Gobierno Vasco ${ }^{79}$ propician la consolidación de las diferentes dinámicas que se originan en el poder institucional. Ejemplo de esta hegemonía cultural generada a partir de la constante retroalimentación de los diferentes agentes, se evidencia en las escasas aproximaciones críticas que se han generado en torno al relato de la

\footnotetext{
${ }_{74}^{74}$ Por ejemplo, Historias Compartidas. El siglo XX en la Colección Kutxa en Kutxa Kultur Artegunea, Basterretxea, Sistiaga y Zumeta. Obra de los últimos años en Okendo Kultur Etxea, Mendiburu y Amable. Obra de los últimos años en la galería Kur Art Gallery, y Balerdi. Obra de los últimos años en la Galería Altxerri. Al igual el Museo de Bellas Artes de Bilbao presentó la exposición Amable, Balerdi, Basterretxea, Chillida, Mendiburu, Oteiza, Sistiaga, Zumeta. Por último, en la ciudad polaca Wroclaw, la otra ciudad seleccionada como capital europea en 2016, se llevaron adelante actividades paralelas que presentaban la ciudad de San Sebastián, por ejemplo, un seminario y una exposición en torno a Eduardo Chillida.

${ }^{75}$ Ormazabal, Mikel, "Henry Moore 'conversa' con Chillida y Oteiza", en El País, 21 de junio de 2016. «https:// elpais.com/ccaa/2016/06/21/paisvasco/1466508683 790366.html» [Consultado el 26 de enero de 2020].

${ }^{76}$ Manterola, Ismael, Maite ditut maite. Transmisioa XX. mendeko Euskal Herriko artean, Andoain, EDO! Argitaletxea, 2017, pp. 97-98.

${ }^{77}$ El último ejemplo, se haría visible en la iluminación navideña de la ciudad, al colocarse arcos luminosos que incorporan las siluetas de las esculturas El peine del viento y La paloma de la paz. Zabaleta, Arantzazu, "la iluminación y el mercado de Navidad se inaugurarán el día 30 con fuegos artificiales", en Noticias de Gipuzkoa, 20 de noviembre de 2019. «https://www.noticiasdegipuzkoa.eus/2019/11/20/vecinos/la-iluminacion-y-el-mercadode-navidad-se-inauguraran-el-dia-30-con-fuegos-artificiales» [Consultado el 26 de enero de 2020].

${ }^{78}$ Marcuse, Heber, El hombre unidimensional, México, Editorial Joaquín Mortiz, 1981, pp. 82-83.

${ }^{79}$ Marzo, Jorge Luis y Badia, Tere, "Las políticas... op. cit.
} 
historia del arte vasco ${ }^{80}$. De ahí la urgencia de mirar el pasado artístico del País Vasco desde otros puntos de mira, interrogando qué otros espacios, prácticas y sujetos fueron silenciados y relegados a los márgenes de este proceso histórico. Pensar desde este afuera, como hemos tratado de reivindicar en este texto, posibilita el cuestionamiento y la desnaturalización de la visión hegemónica, en este caso, en torno al pasado artístico del País Vasco.

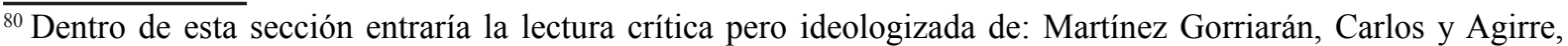
Imanol, Estética de la diferencia: el arte vasco y el problema de la identidad, 1882-1966, Irun, Alberdania, 1995 y la citada lectura crítica del primer autor sobre la figura de Jorge Oteiza. Sin embargo, las principales aportaciones que han tratado este proceso se han efectuado fuera del País Vasco como es el caso de: Marzo, Jorge Luis, "Lo moderno... op . cit. y el apartado "El Estado Autonómico y las nuevas identidades visuales" en Marzo, Jorge Luis y Mayayo, Patricia, Arte en España (1939-2015), Ideas, prácticas, políticas, Madrid, Ediciones Cátedra, 2015, pp. 483-487.
} 